\title{
Subtle Discrimination in the Workplace: A Vicious Cycle
}

\author{
Kristen P. Jones and Dave F. Arena \\ The University of Memphis \\ Christine L. Nittrouer \\ Rice University \\ Natalya M. Alonso \\ University of British Columbia \\ Alex P. Lindsey \\ Indiana University-Purdue University Indianapolis
}

\begin{abstract}
Due to rising pressure to appear egalitarian, subtle discrimination pervades today's workplace. Although its ambiguous nature may make it seem innocuous on the surface, an abundance of empirical evidence suggests subtle discrimination undermines employee and organizational functioning, perhaps even more so than its overt counterpart. In the following article, we argue for a multidimensional and continuous, rather than categorical, framework for discrimination. In doing so, we propose that there exist several related but distinct continuums on which instances of discrimination vary, including subtlety, formality, and intentionality. Next, we argue for organizational scholarship to migrate toward a more developmental, dynamic perspective of subtle discrimination in order to build a more comprehensive understanding of its antecedents, underlying mechanisms, and outcomes. We further contend that everyone plays a part in the process of subtle discrimination at work and, as a result, bears some responsibility in addressing and remediating it. We conclude with a brief overview of research on subtle discrimination in the workplace from each of four stakeholder perspectives-targets, perpetrators, bystanders, and allies-and review promising strategies that can be implemented by each of these stakeholders to remediate subtle discrimination in the workplace.
\end{abstract}

A pregnant job applicant notices a hiring manager avoids eye contact with her during her interview and wonders whether it is because of her growing

Kristen P. Jones and Dave F. Arena, Fogelman College of Business \& Economics, The University of Memphis; Christine L. Nittrouer, Department of Psychology, Rice University; Natalya M. Alonso, Sauder School of Business, University of British Columbia, Vancouver, British Columbia, Canada; Alex P. Lindsey, Department of Psychology, Indiana UniversityPurdue University Indianapolis.

Correspondence concerning this article should be addressed to Kristen P. Jones, Fogelman College of Business \& Economics, University of Memphis, 3675 Central Avenue, FAB 201, Memphis, TN 38152. E-mail: kpjones4@memphis.edu 
baby bump. An overweight retail store associate is placed in the stockroom moving boxes and contemplates whether this is due to her physical appearance. A new employee at a law firm is not invited to happy hour and wonders whether it is because he recently disclosed his bisexuality to a group of coworkers or because he just does not know his colleagues well enough yet to be included in social gatherings. These examples illustrate how subtly discriminatory behaviors can manifest in workplace settings and exemplify the ambiguity that characterizes subtle discrimination. In each of these examples, it is unclear whether the behavior is due to the target's stigmatized characteristic (e.g., pregnancy) or whether the behavior resulted from some other reason unrelated to discrimination (e.g., the manager avoids eye contact with everyone). Because a clear attribution for the behavior cannot be made, it is likely that the targets in each scenario will continue to ruminate on the experience, performing a sort of cognitive gymnastics to try to discern the reason for the treatment they received.

In today's workplace, it is illegal to overtly discriminate against a person based on a variety of protected characteristics (e.g., race, gender, disability status; King \& Cortina, 2010). Furthermore, it is socially unacceptable to discriminate against applicants or employees based on traits that are not job related, even those that may not be legally protected (e.g., sexual orientation, gender identity, attractiveness; Perry, Murphy, \& Dovidio, 2015). As a result, prejudice in the workplace often manifests in subtle ways, such as in the instances previously described. In fact, some scholars have argued that prejudiced individuals rely on subtle discrimination to express bias in a way that does not explicitly violate social norms and expectations for egalitarianism (Crandall \& Eshleman, 2003). Other perpetrators, who believe they are egalitarian, may also express subtle bias by virtue of unconscious processes. Either way, the result is the same: The target individual is left at a disadvantage, and the cause of this inequity is unclear. Indeed, in each of these previous instances, there is uncertainty regarding whether discrimination has actually occurred. Specifically, there is always a possible alternative explanation for the behavior; the interviewer could just be socially awkward, the retail store might legitimately need more help in the stockroom, and the bisexual employee's colleagues may have just forgotten to add his e-mail address to the happy hour list.

An abundance of empirical evidence suggests that subtle discrimination negatively impacts employees and organizations, perhaps to an even greater degree than overt discrimination (see Jones, Peddie, Gilrane, King, $\&$ Gray, 2016, for a review). Although existing research on the topic provides a solid foundation from which to build understanding of subtle discrimination in organizational settings, this area of research is still growing, and many questions remain unanswered. Therefore, our goal in this article is to, first, 
provide a clarifying framework through which to understand the construct of subtle discrimination. Here, we argue for a multidimensional and continuous, rather than categorical, framework for discrimination. That is, in addition to considering the subtlety of discrimination, we assert that scholarship should move toward incorporating other dimensions along which discriminatory instances may vary including formality and intentionality. Second, we propose a view of subtle discrimination that is more dynamic and developmental to allow for a more nuanced understanding of its antecedents, underlying mechanisms, and consequences. In doing so, we argue for the development of more research investigating how distal consequences of subtle discrimination compound over time. Third and finally, we briefly describe the experience of subtle discrimination at work from the perspective of multiple stakeholders including targets, perpetrators, bystanders, and allies while reviewing the most effective strategies for remediation.

\section{What Is Subtle Discrimination?}

Before delving deeper into the manifestations of subtle discrimination in organizations and the experiences of those involved, it is important to clearly define the construct space. This is particularly vital for subtle discrimination, given that there is a fair amount of construct confusion and conflation surrounding this phenomenon in the existing literature. Accordingly, our goal in this section is to not only define subtle discrimination but to situate subtle discrimination in the context of several continuums along which we propose discrimination varies including subtlety, formality, and intentionality.

First, we conceptualize that discriminatory behavior exists on a continuum of subtlety, with subtle discrimination at one end and overt discrimination at the other. We define subtle discrimination as "negative or ambivalent demeanor or treatment enacted toward social minorities on the basis of their minority status membership that is not necessarily conscious and likely conveys ambiguous intent" (Jones, Peddie, et al., 2016, p. 1591). At the other end of the continuum is overt discrimination, which is more conspicuous and can be defined as "a clearly exercised form of unfair treatment with visible structural outcomes" (Van Laer \& Janssens, 2011, p. 1205). In short, we contend that the subtlety of discrimination is driven by how obvious it is that discrimination has occurred in the first place, with subtle discrimination being more nuanced and obscured as compared with overt discrimination, which is more readily apparent and discernable. Again, we emphasize here that discrimination varies on a continuum of subtlety rather than existing as two discrete categories of purely subtle discrimination and purely overt discrimination.

We compare this conceptualization with formal and interpersonal discrimination, which we argue exist on a second continuum along which 
discrimination varies: formality. We assert that the formality of discrimination is another important dimension to consider, with formal discrimination at one end of the spectrum and interpersonal discrimination at the other. Interpersonal discrimination can manifest itself in a number of ways, including but not limited to disrespect, verbal and nonverbal harassment, and general rudeness or hostility toward minorities. Importantly, these behaviors can occur both at work and in social situations more generally (Hebl, Foster, Mannix, \& Dovidio, 2002). In contrast, formal discrimination is job related and thus often has rules, regulations, laws, and sometimes even organizational policies in place to (a) prevent it from occurring in the first place and (b) to facilitate an appropriate response if and when it does occur. One example of formal discrimination would be the decision to not hire and/or promote an employee due to a stigmatizing characteristic that they possess (Hebl et al., 2002). Overall, the formality of a discriminatory instance reflects the extent to which there are job-related implications. Again, we stress that job relatedness is a continuous characterization rather than a discrete categorical distinction between formal and interpersonal discrimination.

Although subtle and interpersonal discrimination are often used interchangeably in extant literature, it is important to note that the distinction between subtlety and formality is that subtlety refers to how obvious it is that a discriminatory instance is related to a stigmatized characteristic of the target, whereas formality refers to the job relatedness of the behavior. Thus, although discrimination can be difficult (subtle) or easy (overt) to detect, it can also be directly related to one's job (formal) or related to social dynamics more generally (interpersonal). Overt discrimination may be obviously related to one's stigmatizing characteristic, but it does not necessarily deny these individuals workplace opportunities in the same way that formal discrimination would. For example, a coworker calling ethnic minorities demeaning terms based on their ethnicity without having any impact on the target's job itself would qualify as an overt manifestation of discrimination that is interpersonal, not formal, in nature (Bobbitt-Zeher, 2011). However, if obviously racist reasoning was used to deny specific targets promotions, pay raises, or desirable job assignments, then this would qualify as a discriminatory instance that is both overt and formal in nature. Likewise, although subtle discrimination is often assumed to be interpersonal, we would argue that an instance of discrimination can be both subtle and formal. For instance, if a Christian is unrightfully chosen for a job over a Muslim individual, but it is not discernable that prejudice was present in the hiring process, this would qualify as an example of discrimination that is both subtle and formal in nature.

Accordingly, we conceptualize subtlety and formality as two related yet distinct dimensions of discrimination. (See Table 1 for more specific 
Table 1. Discriminatory Instances That Vary in Terms of Subtlety and Form

\begin{tabular}{|c|c|c|}
\hline Form & Subtle & Overt \\
\hline Interpersonal & $\begin{array}{l}\text { Julia Smith was working as a field } \\
\text { office manager on a construction } \\
\text { job site. Her first task of the day was } \\
\text { to ensure that the correct amount } \\
\text { of cement had been ordered. She } \\
\text { asked a male laborer whether or } \\
\text { not the order had been placed. He } \\
\text { responded, "I don't know. Isn't that } \\
\text { your job?" She decided to ask the } \\
\text { male superintendent about the } \\
\text { cement order. He did not know } \\
\text { whether or not it had been sent, so } \\
\text { he asked the same laborer. The } \\
\text { laborer told him that the order had } \\
\text { already been processed. }\end{array}$ & $\begin{array}{l}\text { Jennifer Taylor was working as } \\
\text { an administrative assistant for } \\
\text { the president of a construction } \\
\text { company. One of the project } \\
\text { managers stopped at her desk } \\
\text { and asked whether the } \\
\text { president was available. She } \\
\text { responded that he was out of } \\
\text { the office and asked whether } \\
\text { there was anything that she } \\
\text { could help with. The project } \\
\text { manager rolled his eyes and } \\
\text { said, "I don't think that } \\
\text { anyone in a dress can answer a } \\
\text { question about construction." }\end{array}$ \\
\hline Formal & $\begin{array}{l}\text { Elaine Roberts was the only female } \\
\text { superintendent in her construction } \\
\text { company. Her current project was } \\
\text { almost completed, and she was } \\
\text { ready to begin a new project. She } \\
\text { knew that the project managers } \\
\text { would be assigning two new } \\
\text { projects: one large, complicated, } \\
\text { and lucrative office building project } \\
\text { and one small, basic, cheap store. A } \\
\text { male coworker was assigned to the } \\
\text { lucrative project, and she was } \\
\text { assigned to the small store. They } \\
\text { both started working for the } \\
\text { company at the same time and had } \\
\text { similar rates of success in their } \\
\text { previous building projects. }\end{array}$ & $\begin{array}{l}\text { Sarah Walls overheard her male } \\
\text { coworker discussing his recent } \\
\text { pay raise. Although she } \\
\text { received higher performance } \\
\text { evaluations than he did, Sarah } \\
\text { did not receive an increase in } \\
\text { pay. She decided to approach } \\
\text { her male supervisor to ask for } \\
\text { a comparable increase in pay. } \\
\text { He refused and told her that } \\
\text { "Women do not deserve to } \\
\text { make as much as men." }\end{array}$ \\
\hline
\end{tabular}

Note. Adapted from "When Do Women Respond Against Discrimination? Exploring Factors of Subtlety, Form, and Focus," by A. Lindsey, E. King, H. Cheung, M. Hebl, S. Lynch, and V. Mancini, 2015, Journal of Applied Social Psychology, 45, p. 653. Copyright 2015 by Wiley.

instances that vary in terms of subtlety and form.) We certainly acknowledge that these dimensions are correlated (i.e., subtle tends to be interpersonal, and overt tends to be formal); however, we do not believe that subtlety and formality are redundant constructs and thus assert there is value in considering both dimensions to fully understand the many possible manifestations of discrimination. Although we realize this assertion may be met with 
some controversy and skepticism, there is recent empirical work that supports our view. Indeed, Lindsey and colleagues (2015) showed that women could reliably distinguish between factors of subtlety and formality when deciding how they would respond to scenarios depicting various instances of discrimination. Specifically, the findings revealed that although there were no differences in women's abilities to detect interpersonal versus formal discrimination, women were more likely to detect overt as compared with subtle manifestations of discrimination. Additionally, the findings revealed that women were more likely to say that they would take action against discriminatory instances that were overt and formal as compared with those that were more subtle and interpersonal in nature. To the extent that subtlety and formality reflect the same construct, one would expect to observe similar effects across dependent variables of interest, as opposed to the differing effects that the authors observed here. In an effort to examine whether women's actual experiences also varied across these dimensions of discrimination, Lindsey and colleagues (2015) conducted a follow-up study in which they asked women to recall discriminatory incidents that they had experienced or witnessed in the workplace. These incidents were then rated by two independent coders with regard to subtlety and formality. Although the plurality of the incidents recalled were subtle and interpersonal in nature $(33 \%)$, participants also provided discriminatory instances that were overt and interpersonal (28\%), overt and formal (23\%), and subtle and formal (16\%).

In addition to subtlety and formality, researchers might also consider other continuums along which instances of discrimination may vary to more fully understand cases of discrimination. For example, intentionality, the extent to which the discrimination is intentional, is an important component that is often mentioned in various definitions of subtle and overt discrimination. Indeed, subtle discrimination is often described as reflecting ambiguous intent, whereas overt discrimination is often associated with a clear intention to harm the target (Jones, Peddie, et al., 2016). Again, although we agree that the intentionality of discrimination is likely often correlated with the subtlety of discrimination, we argue this is not always the case. Indeed, it is relatively easy to think of instances that are not obviously discriminatory (subtle) but in which people do intend to harm the target. For instance, a Black employee's manager might intentionally dismiss his ideas during a meeting in a way that is not obviously discriminatory (subtle). Furthermore, discrimination might be obvious (overt) but unintentional, as is often the case in situations when someone "puts their foot in their mouth" or says something offensive without thinking but clearly did not intend or plan to harm the target. Although these dimensions are clearly not orthogonal, they are not completely redundant either. Consequently, we contend there is value 
in considering these interrelated dimensions as a set given they more fully capture the construct space of discrimination.

Indeed, there are various constructs (e.g., benevolent sexism, modern racism, incivility, interpersonal mistreatment, bullying, microaggressions) in the literature that reflect subtle, overt, interpersonal, formal, intentional, and unintentional manifestations of discrimination directed at oneself and others. Rather than continuing to proliferate and propagate new terminologies, we reason that instead focusing on higher level dimensions such as subtlety, formality, and intentionality while also considering how targets and others recognize and take action against these various types of discrimination could serve as a unifying framework. This may allow for more theoretical precision when discerning whether findings from differing research streams are comparable with one another, in addition to providing guidance when studying new ideas regarding manifestations, targets, and remediation of discrimination in the future.

Finally, it is important to note that although subtle discrimination may seem less severe and damaging when compared with more conspicuous discriminatory instances, recent research claims that the exact opposite may be true or that subtle discrimination may actually be more damaging when compared with its overt counterpart. Indeed, a recent meta-analysis on this topic concluded that subtle discrimination had more detrimental effects on employee well-being, job attitudes, and even organizational outcomes when compared with discrimination that was more overt in nature (Jones, Peddie, et al., 2016). The authors used an attributional ambiguity rationale (e.g., Crocker \& Major, 1989) to explain these findings, arguing that the inherently ambiguous nature of subtle discrimination makes it more difficult for targets to attribute the negative behavior externally, thereby increasing the likelihood that targets will blame themselves for such incidents. Importantly, the ambiguity surrounding subtle discrimination likely prolongs the attribution process, causing targets to ruminate on the incident long after it occurs because they have no clear cause to reference. Therefore, even if targets attribute the behavior to themselves or to something external, they may continue spending time wavering between various explanations for the incident, which can be emotionally and cognitively taxing. Thus, although somewhat counterintuitive, the fact that subtle discrimination is not obvious may be the characteristic that makes it so harmful to targets. These harmful effects may build and accumulate over time, as discussed in the next section on subtle discrimination's cyclical nature.

\section{The Cyclical Nature of Subtle Discrimination}

Whereas past research on subtle discrimination-and discrimination more generally-has traditionally focused on discrimination as a cause-and-effect 
process (i.e., discrimination occurs, and these are its consequences; Salvatore \& Shelton, 2007), we contend this view of discrimination is oversimplified and insufficient to building a holistic understanding of the underlying processes involved in subtle discrimination. We instead conceptualize discrimination as a reciprocal process that develops and changes over time. Although we recognize that all types of discrimination-both subtle and overt-are characterized by cyclical processes, we assert that it is particularly important to address the cyclical processes underlying subtle discrimination. Indeed, because subtle discrimination is ambiguous, the dynamic processes that result from subtle discrimination are also less apparent and may even be unknown to the focal actors, making it all the more important to investigate its cyclical nature. It is our hope that this more dynamic view of subtle discrimination will facilitate a better understanding among scholars and practitioners of how subtle discrimination manifests over time in organizational settings and, thus, a better understanding of how to address and remediate it. Below, we provide four reasons justifying a movement toward a developmental perspective of subtle discrimination.

\section{Within-Person Changes in Role Occupancy}

Our first argument in support of a developmental perspective of subtle discrimination is the fact that the same individual may occupy multiple roles in the subtle discrimination process at different points in time based on prior experiences. For example, a target of subtle discrimination may feel disgruntled and subsequently become a perpetrator at a later point in time. Alternatively, a target may become more empathetic as a result of his or her experience with subtle discrimination and become an ally for another target of subtle discrimination at a later occasion. As another example, a perpetrator of subtle discrimination might later become a target or a bystander. In other words, employees' present and past experiences with subtle discrimination are continuously shaping their future experiences with subtle discrimination.

This notion was supported by recent research illustrating the cumulative detrimental effects of subtly discriminatory behaviors at work, asserting "just like the common cold, common negative behaviors can spread easily and have significant consequences for people in organizations" (Foulk, Woolum, \& Erez, 2016, p. 50). Specifically, the authors found that low-intensity negative behaviors like rudeness can be "contagious" in that experiencing rudeness predicted the subsequent expression of rudeness in future interactions with different partners. Thus, participants who were targeted with rudeness were more likely to become perpetrators of rudeness toward a different person at a later point in time. 
In light of these findings, our primary contention is that everyone plays a part in the "problem" of subtle discrimination. It is not just a perpetrator problem that can be fixed by changing the "bad people's" attitudes and behaviors. It is not just a target problem that can be fixed by teaching victims how to cope with or curb subtle discrimination. The point is that everyone can be a perpetrator at some point, and everyone can also be a target at some point. Indeed, we argue there is within-person change in the extent to which every individual occupies the roles of target, perpetrator, ally, and bystander. Thus, we must work together and take responsibility for the part that we all play (knowingly or not) in the manifestation of subtle discrimination at work.

\section{The Dynamic Nature of Relationships}

Drawing from social and developmental psychology, we know that relationships build and change over time. Indeed, social contact theory suggests that increased social contact with outgroup members can help to break down prejudiced attitudes (Allport, 1954). This pattern is likely attributable, in part, to the fact that, in the absence of individuating information about an outgroup member, people are more likely to rely on stereotypes about that outgroup when interacting with a member of that group. Therefore, as we learn more about a person, we tend to rely more on that new information and less on stereotypes. Similarly, disclosure research has shown that sharing personal information with others can foster intimacy, liking, and trust (Collins \& Miller, 1994; Manne et al., 2004; Turner, Hewstone, \& Voci, 2007). Therefore, because relationships are constantly changing over time as people have new experiences with and learn more about each other, examining the extent to which an individual perceives, witnesses, or engages in subtle discrimination with a particular person at a single snapshot in time is insufficient to fully understanding the experience and consequences of subtle discrimination within a particular relationship.

For example, when a newly hired employee is slighted by her colleagues during team meetings and assigned less challenging tasks, she perceives this as a sign that her coworkers do not trust her work and view her as less competent. As a result, she finds it difficult to trust and open up to others and subsequently becomes even more isolated from her coworkers (even those who did not subtly discriminate against her in the first place), which in turn exacerbates the problem. This example illustrates how subtle discrimination can affect its targets in a way that may further worsen their situation in the future. Therefore, attributions of blame to the target may appear justified at a single point in time (e.g., "they are mean; they bring it on themselves") but are actually the result of an ongoing cycle of discrimination that influences both the target and the perpetrators. Consequently, it is not sufficient to look at a 
single party's perspective nor is it sufficient to examine a single point in time. The occurrence of subtle discrimination is affected by previous interactions and also functions to shape future experiences. Furthermore, the relational context in which subtle discrimination can occur is not limited to a single one-on-one interaction affecting two employees but may spiral into other relationships with other parties. In other words, subtle discrimination does not occur within a vacuum of a single dyadic interaction. Indeed, team-level processes and outcomes as well as the contextual climate for subtle discrimination may be shaped (either positively or negatively) as a result of other individuals who are watching, condoning, confronting, or even potentially jointly participating in subtle discrimination.

\section{Perceptual Versus Absolute Subtle Discrimination}

In addition to underscoring the importance of relationship and team dynamics, the example above highlights the distinction between perceptual and absolute subtle discrimination, prompting critical questions for consideration. For instance, if targets, perpetrators, allies, and bystanders vary in the extent to which they view the same objective behavior as subtly discriminatory, can an objective definition of subtle discrimination exist or is it all in the eye of the beholder? Is subtle discrimination only damaging if an individual recognizes it and/or categorizes it in a certain way?

As discussed in the opening of this article, recent work by Lindsey and colleagues (2015) examining women's tendency to recognize discrimination directed at others while minimizing their own experiences of discrimination provides a starting point for disentangling some of these issues. In this study, women were asked to imagine either themselves or another woman being discriminated against at work in a manner that was either subtle or overt and to subsequently indicate (a) whether they recognized the behavior as discrimination and (b) whether they would take action against the behavior. Results suggested women were more likely to perceive the same behavior as discrimination when it was directed at another woman as compared with when it was directed at themselves. Furthermore, women were more likely to recognize and take action against overt forms of discrimination as compared with subtle forms of discrimination. These patterns were partially replicated in a follow-up field study in which the authors asked participants to recall actual experiences of workplace discrimination directed at both themselves and others. At the very least, this evidence suggests subtle discrimination may be, in part, in the eye of the beholder and further supports our contention that exploring subtle discrimination from a single perspective contributes to a limited understanding of its antecedents, underlying mechanisms, and consequences. To be clear, the fact that the experience of subtle discrimination can be subjective does not mean it is innocuous. Indeed, even 
those who do not perceive disparate treatment as discrimination may still be harmed by the behavior.

Variation in Effects of Subtle Discrimination as a Function of Repeated Exposure Our final argument in support of a developmental perspective of subtle discrimination is that a cross-sectional perspective does not account for possible accumulation effects. More specifically, targets may be differentially affected by subtle discrimination as a function of repeated exposure to subtly negative treatment. Though empirical work on this phenomenon is limited, we speculate here that repeated exposure to subtle discrimination may change how people are affected by the behavior, further highlighting the importance of a dynamic view of subtle discrimination as it manifests in workplace settings. Although some research has indicated repeated exposure to mistreatment may build resilience to such mistreatment, other work suggests seemingly small instances of discrimination accumulate to produce substantial disadvantage over time. Below, we describe these two opposing perspectives in more detail.

Albeit somewhat provocative, one possibility is that targets may be less affected by subtly negative treatment to the extent that they tend to incur it more frequently. This notion is consistent with psychological adaptation theory (Helson, 1964) in that people may subconsciously adjust to negative situations by adapting their expectations to be consistent with that new (negative) norm, and thus, they become inoculated to additional similarly stressful experiences. In other words, people who are repeatedly treated in a discriminatory manner might develop "thicker" skin over time, learning more effective coping mechanisms for dealing with the stress of being a target because they are confronted with these situations more often and have more opportunities to "practice." In contrast, targets who incur subtle discrimination less frequently may be more jarred by a single occurrence because it is very different from their norm, and they have not learned how to effectively cope with the stress. From this perspective, prolonged exposure to subtle discrimination may, in a sense, help targets build immunity to its damaging consequences.

Although we are not aware of any empirical evidence addressing the impact of repeated exposure to subtle discrimination specifically, two existing studies suggest the potential of a gradual adaptation to general negative treatment in the workplace. The first study examined the separate and conjoint effects of three different forms of workplace harassment-ethnic, sexual, and generalized workplace harassment-on employees' work-related, psychological, and physical health outcomes (Raver \& Nishii, 2010). Results suggested an inurement effect (i.e., adjusting to hardships) of workplace harassment wherein a single form of harassment was harmful, but additional forms of 
harassment after a certain level did not lead to additional negative outcomes. Though the mistreatment here was more overt in nature, we reason a similar phenomenon may occur when people are repeatedly mistreated in a subtly discriminatory manner. Similarly, recent work examining obese versus nonobese workers' ability to handle supervisor mistreatment found evidence that suggested a buffering effect of obesity (Johnson \& Griffith, 2016). Specifically, the results showed that obese employees reported less severe negative health outcomes and took fewer sick days after experiencing abusive supervision as compared with their nonobese coworkers experiencing the same mistreatment. The authors reasoned this was because of obese workers' consistent exposure to interpersonal mistreatment throughout their lives, which allowed them to adapt to stressful experiences. Indeed, these results are consistent with the overarching notion of psychological resilience, or the general finding that people tend to recover relatively well following traumatic life events or stressful conditions (e.g., premature death of spouse, death of child, death of parents, divorce; Lucas, 2007).

That said, we are not arguing that because the targets of subtle discrimination may adapt, they are therefore equipped to handle all of the negative treatment they experience. Indeed, there should be no reason that minority employees need to be equipped with extra resilience. Further, as previously mentioned, there is recent research that addresses the negative intrapersonal consequences of subtle discrimination (Jones, Peddie, et al., 2016). We are simply arguing that when delineating the most effective coping strategies, some of the most frequent targets of subtle discrimination may be exemplars for how to best "keep on keeping on."

Whereas the above studies suggest a "skin-thickening" effect, we next suggest that the opposite could also be true. Subtle discrimination may be increasingly harmful with repeated exposure due to the fact that it is a prolonged state wherein an individual is constantly attempting to make clear attributions for others' ambiguously discriminatory treatment. We further argue this prolonged state of ambiguity is increasingly depleting for cognitive and emotional resources as time goes on. Indeed, this notion of an accumulation effect has been reflected in scholar Virginia Valian's work, which argues that women incur a substantial disadvantage when seemingly small instances of discrimination accumulate over time as compared with men (Valian, 1998). We contend that this is an important area for future work, particularly because of the pervasive nature of subtle discrimination in daily contemporary life (Dovidio \& Gaertner, 1998; McConahay, 1983; Swim, Aikin, Hall, \& Hunter, 1995). Regardless of whether it is a skin-thickening effect or an accumulation effect, a dynamic, developmental perspective of subtle discrimination must be adopted in order to examine these potential complexities. 


\section{Research on Subtle Discrimination and Strategies for Remediation}

In the previous section, we mentioned that everyone plays a part in the process of subtle discrimination: targets, perpetrators, bystanders, and allies. Below, we provide a brief summary of some of the extant research on subtle discrimination that has been conducted from the perspective of each of these stakeholders, highlighting remediation strategies that can be implemented by occupants in each of these roles. Although we do not review organizational strategies for discrimination reduction in light of space constraints, we emphasize that organizations hold enormous power in shaping context, both inside and outside of the workplace, and can engage in specific strategies, particularly through recruitment and diversity training, to promote an inclusive environment in an effort to reduce subtle discrimination (see Hebl, Ruggs, Martinez, Trump-Steele, \& Nittrouer, 2015, and King \& Gilrane, 2015, for additional reviews).

\section{Target Experience of Subtle Discrimination}

There are a myriad of opportunities for bias to emerge before the formal selection process even begins. As a prime example of how subtle bias emerges in a meaningful way before people formally seek employment, Milkman, Akinola, and Chugh (2015) sent identical e-mails to over 6,000 professors in which the researchers posed as prospective graduate students, varying only the ethnicity (e.g., White, Black, Hispanic, Indian, Chinese) and gender of the sender's name. They found that across all disciplines and institutions, professors (including women and ethnic minority faculty) were more likely to respond to the White male prospective graduate students as compared with female and ethnic minority prospective graduate students. Other research has found subtle bias can restrict social networks, which are important sources of job information and opportunities Konrad, Seidel, Lo, Bhardwaj, \& Qureshi, 2015).

Subtle bias may also seep into recruitment processes. For example, recruiters may place undue emphasis on factors such as university prestige and grade point average, which have been shown to be poor predictors of job performance (Bryant, 2013; Rivera, 2012). These metrics have differential adverse impact, and thus, in addition to being unrelated to most job descriptions (the caveat being entry-level jobs), they can also disadvantage certain groups. Furthermore, deeply ingrained negative stereotypes may shape how application materials are perceived and, therefore, disadvantage minority groups in subsequent hiring decisions (Madera, Hebl, \& Martin, 2009). Finally, insufficient or inauthentic diverse recruitment material may act as a subtle barrier to minority applicants who see it as a reflection of the organization's diversity climate (Avery, 2003). 
Beyond recruitment, many people who make selection decisions tend to rely on less valid selection measures that may inadvertently disadvantage minority applicants despite the fact that a number of selection measures with high predictive validity and low adverse impact have been identified (Schmidt \& Hunter, 1998). For instance, an increasing number of hiring managers are relying on social media information (e.g., Facebook, Myspace, Twitter; V. R. Brown \& Vaughn, 2011) as well as credit scores (Bernerth, Taylor, Walker, \& Whitman, 2012) to help them screen and select applicants. Indeed, these trends are disconcerting insofar as these sources reveal information to recruiters and hiring managers that is unrelated to the job but may bias the selection process.

Unstructured interviews, one of the most widely used hiring tools in selection, present a tremendous opportunity for subtle bias due to their interpersonal nature. For instance, Barrick, Swider, and Stewart (2010) discovered that the informal "rapport building" (e.g., non-job-related chitchat) that took place between a candidate and an interviewer before a structured interview began predicted subsequent job offers. Indeed, interviewers may be more open and friendly with individuals who are more similar to them, leading to better rapport building with those candidates and putting dissimilar others at a disadvantage.

A foundational social psychology study conducted by Word, Zanna, and Cooper (1974) sheds further light on the ways that subtle bias can manifest in face-to-face interviews. Specifically, these researchers found that naïve, White job interviewers demonstrated more physical distance, had a shorter interview length, and had higher rates of speech errors with Black applicants as compared with White applicants. In a second experiment, interviewers were trained to treat half of the naïve, White applicants in the same way as Black applicants had been treated in the first study (e.g., more physical distance, shorter interview length, and higher rates of speech errors). These applicants were judged to perform less adequately and appeared more nervous in the interview situation as compared with the subjects treated like the White applicants from the first study. Thus, subtle bias can unconsciously shape the interviewer's behavior and drive the interview interaction in a completely different (and unfavorable) way for a minority-group interviewee versus a majority-group interviewee.

Once on the job, minority employees are also at risk of falling victim to subtle discrimination by supervisors, coworkers, and potentially customers-as well as when serving as part of a team. Indeed, minority employees report experiencing greater on-the-job incivility than majority employees, and this can result in a number of negative individual-as well as organizational-outcomes (Cortina, Kabat-Farr, Leskinen, Huerta, \& Magley, 2013; Fox \& Stallworth, 2005). This finding is supported by recent 
research conducted by Jones, Sabat, Lindsey, Ahmad, and Arena (2016), which revealed that ethnic minority women reported lower intentions to pursue employment with an organization when they were treated with subtle discrimination by a confederate interviewer-arguably, this was seen as a proxy for the climate they would experience once hired. Interestingly, this effect was mediated by increased stress. Thus, a compendium of research suggests that a variety of minority employees report experiencing subtle discrimination both before they are hired and while they are on the job.

In light of the abundance of research suggesting subtle discrimination affects targets at virtually every stage of (and even prior to) the employment cycle, scholars have examined compensatory strategies the target can enact to reduce or eliminate the interpersonal (subtle) discrimination he/she may experience (Singletary \& Hebl, 2009). One compensatory strategy found to be particularly effective at reducing interpersonal discrimination reported by a target job applicant was displaying increased positivity, operationalized by instructing targets to say things like "I am really excited about the possibility of working here," smiling often, and appearing pleasant and generally upbeat (Singletary \& Hebl, 2009, p. 800). However, this strategy may not be a longterm solution given the taxing emotional labor involved.

Another strategy that can be implemented by targets is an acknowledgment strategy, which involves directly acknowledging a readily apparent marginalized characteristic (e.g., obesity, race, gender, disability). Extant scholarship on stigma acknowledgment has shown it can be effective in reducing the anxiety and discomfort nonstigmatized individuals may feel when interacting with a marginalized other (Hebl et al., 2015; Lyons et al., 2016). Although this evidence suggests acknowledgment may be a fruitful strategy for addressing subtle bias in certain contexts, other research indicates that acknowledgment is less effective when interviewing for a gender-incongruent position (when acknowledging gender; Wessel, Hagiwara, Ryan, \& Kermond, 2014) and for individuals who are seen as responsible for their stigmatization (e.g., obesity, drug addiction; Hebl \& Kleck, 2002) unless information about an uncontrollable cause is also given (DeJong, 1980). Clearly, further examination is needed to better understand the impact of this strategy on subtle bias for different marginalized identities and across contexts.

An individuation strategy involves providing counterstereotypical information that addresses concerns about the target individual (see Neel, Neufeld, \& Neuberg, 2013, for examples) and has also been found to be effective at reducing subtle discrimination (Barg, Armstrong, Hetz, \& Latimer, 2010; King \& Ahmad, 2010). For example, interpersonal hostility reported by women wearing a pregnancy prosthesis when applying for a retail job was reduced when they provided counterstereotypical information that addressed 
the hiring manager's pregnancy-related concerns (e.g., lack of commitment, inflexibility; Morgan, Walker, Hebl, \& King, 2013). However, individuation may not always be a viable strategy, particularly if the counterstereotypic information provided violates prescriptive stereotypes about the target's group (Rudman \& Phelan, 2008).

Interestingly, engaging in these prejudice reduction strategies has been found to not only address bias in others but also constitute active/problemfocused coping, which helps targets internally manage experiences of subtle bias. Active coping strategies (e.g., confronting bias, strongly identifying with a stigmatized identity in the face of prejudice) have been favorably compared with passive/emotion-focused strategies (e.g., avoiding prejudiced individuals, ignoring discrimination), which have been linked to detrimental target health outcomes (Mossakowski, 2003; Noh \& Kaspar, 2003; see Noh, Beiser, Kaspar, Hou, \& Rummens, 1999, for an exception). Whereas extant scholarship on this topic has largely focused on racial stigma, future research could broaden the scope of this literature to consider new and existing coping strategies and how they may function across identities.

\section{Perpetrator Experience of Subtle Discrimination}

Despite living in a society that generally strives toward egalitarianism, even individuals with good intentions may struggle to avoid discriminatory behavior due to unconscious bias (Devine \& Monteith, 1999). Thus, in line with our previous discussion of the dimensions on which discrimination can vary, a pressing issue to consider is the degree to which perpetrators intend to discriminate (e.g., perhaps, the well-intentioned are unaware, or the illintentioned are too busy regulating their overt behaviors to be aware of their subtle ones). Indeed, research on victimization (Jensen, Patel, \& Raver, 2014) and incivility (Cortina, 2008) suggests that discrimination, at times, can be subtle but also conscious and intentional. For example, Jensen and colleagues (2014) found that much of the covert victimization reported by employees targeted for overachieving was perceived to be both subtle and intentional, such as the intentional withholding of information and exclusion from team tasks.

However, many perpetrators of subtle discrimination are likely to be low on the intentionality continuum. Previous work suggests that awareness of implicit biases is a critical step in meaningfully reducing unintentional discrimination (Perry et al., 2015). Indeed, some scholars have even argued that individuals cannot be blamed for implicit biases of which they are unaware (Saul, 2013). Interestingly, research has suggested that awareness of subtle discrimination may depend, in part, on individual difference factors, indicating that individuals who were higher in external motivation to respond in a nondiscriminatory manner as well as higher in self-monitoring were more 
aware of their own racial biases (Perry et al., 2015). Similarly, in a survey of 4,732 medical students examining implicit bias toward overweight individuals, Phelan and colleagues (2014) found implicit biases were stronger for participants who had a lower body mass index, were male, and were nonBlack. Taken together, these findings suggest that implicit biases can vary along several cognitive and demographic factors. Although some individual traits may make us more or less aware of our implicit biases, it is important to note that awareness of implicit biases is a necessary but not sufficient condition for behavioral change. Extant research supports the notion that everyone has implicit and automatic stereotypes that may contribute to expressing prejudice in subtle ways (Madera \& Hebl, 2012; Miller et al., 2013).

Assuming a person is aware of his or her subtle bias, there are emotional costs involved in making a decision that runs counter to social norms for egalitarianism. One of the most common emotions perpetrators battle during the discrimination process is guilt, a mechanism that motivates people to alter their actions in such a way that discourages deviance and promotes socially acceptable behavior (Amodio, Devine, \& Harmon-Jones, 2007). Research has suggested guilt may be an effective means through which discrimination can be reduced (Iyer, Leach, \& Crosby, 2003). To demonstrate this point, Monteith, Voils, and Ashburn-Nardo (2001) conducted a study in which participants were made aware of their implicit biases. Interestingly, after being informed of their implicit prejudices, most participants experienced some form of guilt. Importantly, this study highlights that once an individual is privy to the fact that they may be vulnerable to discriminatory behavior, self-regulatory emotions like guilt may play a promising role in attenuating instances of discrimination.

\section{Bystander Experience of Subtle Discrimination}

In addition to targets and perpetrators, nontarget bystanders can also be negatively affected by witnessing subtle discrimination. Indeed, extant research suggests that witnessing subtle discrimination can invoke increased negative affect (Ajrouch, Reisine, Lim, Sohn, \& Ismail, 2010), emotional discomfort (Borders \& Liang, 2011), and distress (Schmader, Croft, Scarnier, Lickel, \& Mendes, 2012) in bystanders and has also been shown to trigger negative feelings about one's organization as a whole (Caza \& Cortina, 2007). In addition to taking a toll on affect and job attitudes, experimental evidence suggests that witnessing subtle (as compared with overt) discrimination can lead to a decrease in both cognitive and creative performance in nontarget bystanders (Arena, Jones, King, \& Sabat, 2016; Porath \& Erez, 2009). Thus, subtle discrimination is damaging to everyone involved, not just focal actors (Miner-Rubino \& Cortina, 2007), and can translate into an 
organizational-level threat that multiplies with the number of individuals who witness the behavior.

One potential remediation strategy bystanders might use is to punish or retaliate against the perpetrator. For instance, Reich and Hershcovis (2015) found participants who witnessed a perpetrator subtly discriminate evaluated that perpetrator significantly more negatively in a work-related evaluation as compared with a control. Here, participants witnessed a confederate subtly discriminate against another confederate through negative body positioning, vocal tones, and undermining the person's ideas in an uncivil manner. Some scholars have suggested that bystanders may punish perpetrators for violating justice norms (O'Reilly, Aquino, \& Skarlicki, 2016; Turillo, Folger, Lavelle, Umphress, \& Gee, 2002), which can occur through a variety of ways, including retaliation, ostracism, neglect, and negative affect toward perpetrators (Reich \& Hershcovis, 2015; Schmader et al., 2012; Smart \& Leary, 2009; Turillo et al., 2002). However, it has been shown that punishing or retaliating against a perpetrator of subtle discrimination does not lead to increased positive affect toward the target of the discriminatory remark. However, because of the interpersonal costs that perpetrators incur from observers, they may be less likely to discriminate in the future (Reich \& Hershcovis, 2015).

Another strategy that bystanders may implement to remediate subtle discrimination is confronting the perpetrator and condemning the behavior directly. Despite generally negative connotations of the term confrontation, recent work emphasizes that confrontation is simply an expression of disapproval toward the perpetrator of discrimination and does not have to be a heated exchange in order to be effective (Ashburn-Nardo, Morris, \& Goodwin, 2008; Shelton, Richeson, Salvatore, \& Hill, 2006). Indeed, confronting prejudice can both empower confronters and discourage perpetrators through increased negative affect and guilt (Czopp, Monteith, \& Mark, 2006). However, extant research has found that this confrontation does not always occur in workplace scenarios due to the ambiguity of subtly discriminatory comments (Jones, Peddie, et al., 2016) or hesitation to take on the responsibility of confronting a perpetrator (Ashburn-Nardo, Blanchar, Petersson, Morris, \& Goodwin, 2014; Ashburn-Nardo, Morris, \& Goodwin, 2008). Furthermore, in some instances, confrontation may even be discouraged due to the fact that bystanders do not wish to be victimized themselves (Porath \& Erez, 2009). The larger problem associated with failing to confront discrimination is that it could potentially reinforce a workplace culture in which subtle discrimination is viewed as acceptable (Benokraitis, 1997). Clearly, scholarship should continue to explore the boundary conditions and effectiveness of various remediation strategies that can be implemented by bystanders. 


\section{Ally Experience of Subtle Discrimination}

In addition to people who simply witness subtle discrimination, we also address the role of allies in the process of subtle discrimination. Allies are defined by K. T. Brown and Ostrove (2013) as "individual[s] not only committed to expressing as little prejudice as possible, but also invested in addressing social inequality" (p. 2211). The latter part of this definition is particularly important and may be what separates allies from more common bystanders. Whereas average bystanders may be motivated to avoid expressing prejudice, true allies distinguish themselves through their desire to promote social justice and their willingness to take action. It is important to note that although allies are generally thought of as dominant group members who combat prejudice and promote the support of less dominant groups (e.g., heterosexual allies to lesbian, gay, bisexual, and transgender [LGBT] individuals, male allies to women, and White allies to ethnic minorities; Broido, 2000; K. T. Brown \& Ostrove, 2013; Reason, Millar, \& Scales, 2005), allies can also be individuals who are themselves members of one stigmatized group serving another (e.g., lesbian allies to gay men; Brooks \& Edwards, 2009). However, it is also worth mentioning that research suggests nonstigmatized allies may be particularly effective at reducing prejudice when they do decide to address and confront discrimination (Shelton \& Stewart, 2004).

Several scholars have emphasized the importance of ally support in addressing both subtle and overt discrimination and are calling for further exploration into ally strategies for bias reduction (K. T. Brown \& Ostrove, 2013; Lindsey, King, McCausland, Jones, \& Dunleavy, 2013; Sabat, Martinez, $\&$ Wessel, 2013). Indeed, through a series of qualitative and quantitative studies, K. T. Brown and Ostrove (2013) uncovered that ethnic minorities view White individuals as allies when they exhibit (a) affirmation (e.g., being respectful, nonjudgmental, and interested in ethnic minorities), and (b) informed action (e.g., being knowledgeable of their own and other racial identities, taking action to address their own biases, and proposing actions to address instances of discrimination). The informed piece of the informed action characteristic should not be overlooked and speaks to a potential boundary condition of ally behaviors; namely, that allies will want to make sure that their behaviors are desired and appropriate before engaging in them as to avoid undermining targets of discrimination. This is similar to a concept that has gained some traction in communities of interest and advocacy circles-consensual allyship-or the idea that both parties (i.e., the ally and the target) must consent to the ally providing support to maximize the effectiveness of the behavior (Taylor, 2014). We contend that this notion deserves more careful consideration in the research literature and that this concept may be especially important to consider when addressing subtle discrimination, which is often and by definition equivocal in nature. 
Research has suggested a variety of bias-reduction strategies allies can implement to support and advocate for stigmatized individuals (Sabat et al., 2013). For instance, allies can engage in a variety of cognitive techniques to reduce their own implicit bias such as disassociating stereotypic information with stigmatized individuals, recalling favorable counterstereotypes, and practicing mindfulness (Blair, 2002; Lueke \& Gibson, 2016). In addition to internally focused strategies, allies can provide public and interpersonal support by receiving stigma disclosure with warmth and positivity, attending educational/support events (Sabat et al., 2013), setting positive social norms, and using their influence to positively impact stigmatized individuals through mentoring (Hebl et al., 2015). Especially in the case of subtle bias, where targets of discrimination can more easily be dismissed as "complainers" for identifying prejudice, allies can use their nontarget, in-group status to more effectively challenge perpetrators (Gulker, Mark, \& Monteith, 2013).

Despite their privileged position for affecting change, willing allies may not always be present or recognize subtle prejudice. Future research should also continue exploring the question of whether effective allies can be bought or built. That is, are the knowledge and skills required for effective allyship trainable, or should organizations instead focus on selecting individuals with the requisite abilities and characteristics to be effective allies? The answer, we suspect, is that both of these paths to effective allyship could work, and they should likely be combined to maximize our potential for creating inclusive work environments.

\section{Conclusion}

To conclude, workplace discrimination varies on a variety of related but independent dimensions including subtlety-the extent to which it is obviously tied to a target's stigmatized characteristic (i.e., overt as compared with subtle), formality - the extent to which it has direct job-related implications for the target (i.e., formal as compared with interpersonal), and intentionality of the perpetrator. In light of strong contemporary norms for egalitarianism, subtle discrimination pervades modern workplaces-particularly when perpetrators experience cognitive dissonance between this norm and their beliefs. Due to its equivocal nature, subtle discrimination is difficult to detect, address, and remediate and is, therefore, particularly threatening to employee well-being as well as organizational functioning. Subtle discrimination exists on a developmental trajectory that is influenced by prior experiences and has implications for shaping future manifestations of subtle discrimination in a specific workplace. A more dynamic conceptualization of subtle discrimination allows us to acknowledge within-person changes in an individual's occupancy of the roles of target, perpetrator, bystander, and 
ally and to examine important possibilities like adaptation or accumulation effects of repeated exposure to subtly negative workplace behavior. Furthermore, a more nuanced understanding of how subtle discrimination manifests in workplace settings can be achieved when we consider multiple perspectives simultaneously, which may also help shed light on issues related to perceptual versus absolute subtle discrimination. Importantly, everyone plays a part in the cycle of subtle discrimination and therefore bears responsibility for addressing and remediating it in their workplace. Although we are all susceptible to subtly discriminating against others at work, it is this awareness of our potential role as perpetrators, perhaps due to an unconscious bias, that must motivate us to work hard (as targets, bystanders, and allies) to reduce it.

\section{References}

Ajrouch, K. J., Reisine, S., Lim, S., Sohn, W., \& Ismail, A. (2010). Perceived everyday discrimination and psychological distress: Does social support matter? Ethnicity \& Health, 15, 417-434. https: //doi.org/10.1080/13557858.2010.484050

Allport, G. W. (1954). The nature of prejudice. Oxford, UK: Addison-Wesley.

Amodio, D. M., Devine, P. G., \& Harmon-Jones, E. (2007). A dynamic model of guilt: Implications for motivation and self-regulation in the context of prejudice. Psychological Science, 18, 524-530. https://doi.org/10.1111/j.1467-9280.2007.01933.x

Arena, D., Jones, K. P., King, E. B., \& Sabat, I. E. (2016, April). The effect of observing subtle discrimination on bystander creativity and interpersonal perceptions. In K. P. Jones (Chair), The trouble with subtle: Boundary conditions of subtle discrimination outcomes. Symposium conducted at the 31st Annual Conference of the Society for Industrial Organizational Psychology, Anaheim, CA.

Ashburn-Nardo, L., Blanchar, J. C., Petersson, J., Morris, K. A., \& Goodwin, S. A. (2014). Do you say something when it's your boss? The role of perpetrator power in prejudice confrontation. Journal of Social Issues, 70, 615-636. https://doi.org/10.1111/josi.12082

Ashburn-Nardo, L., Morris, K. A., \& Goodwin, S. A. (2008). The confronting prejudiced responses (CPR) model: Applying CPR in organizations. Academy of Management Learning \& Education, 7, 332-342. https://doi.org/10.5465/AMLE.2008.34251671

Avery, D. R. (2003). Reactions to diversity in recruitment advertising-Are differences black and white? Journal of Applied Psychology, 88, 672-679. https://doi.org/10.1037/0021-9010.88.4.672

Barg, C. J., Armstrong, B. D., Hetz, S. P., \& Latimer, A. E. (2010). Physical disability, stigma, and physical activity in children. International Journal of Disability, Development and Education, 57, 371382. https://doi.org/10.1080/1034912X.2010.524417

Barrick, M. R., Swider, B. W., \& Stewart, G. L. (2010). Initial evaluations in the interview: Relationships with subsequent interviewer evaluations and employment offers. Journal of Applied Psychology, 95, 1163-1172. https://doi.org/10.1037/a0019918

Benokraitis, N. V. (1997). Subtle sexism: Current practice and prospects for change. Thousand Oaks, CA: Sage.

Bernerth, J. B., Taylor, S. G., Walker, H. J., \& Whitman, D. S. (2012). An empirical investigation of dispositional antecedents and performance-related outcomes of credit scores. Journal of Applied Psychology, 97, 469-478. https://doi.org/10.1037/a0026055

Blair, I. V. (2002). The malleability of automatic stereotypes and prejudice. Personality and Social Psychology Review, 6, 242-261. https://doi.org/10.1207/S15327957PSPR0603_8

Bobbitt-Zeher, D. (2011). Gender discrimination at work: Connecting gender stereotypes, institutional policies, and gender composition of workplace. Gender \& Society, 25, 764-786. https: //doi.org/10.1177/0891243211424741 
Borders, A., \& Liang, C. T. H. (2011). Rumination partially mediates the associations between perceived ethnic discrimination, emotional distress, and aggression. Cultural Diversity and Ethnic Minority Psychology, 17, 125-133. https://doi.org/10.1037/a0023357

Broido, E. M. (2000). The development of social justice allies during college: A phenomenological investigation. Journal of College Student Development, 41, 3-18.

Brooks, A. K., \& Edwards, K. (2009). Allies in the workplace: Including LGBT in HRD. Advances in Developing Human Resources, 11, 136-149.

Brown, K. T., \& Ostrove, J. M. (2013). What does it mean to be an ally? The perception of allies from the perspective of people of color. Journal of Applied Social Psychology, 43, 2211-2222. https: //doi.org/10.1111/jasp.12172

Brown, V. R., \& Vaughn, E. D. (2011). The writing on the (Facebook) wall: The use of social networking sites in hiring decisions. Journal of Business and Psychology, 26, 219-225. https://doi.org/10. 1007/s10869-011-9221-x

Bryant, A. (2013, June 19). In head-hunting, big data may not be such a big deal. The New York Times. Retrieved from http://www.nytimes.com/2013/06/20/business/in-head-hunting-bigdata-may-not-be-such-a-big-deal.html?_r=0

Caza, B. B., \& Cortina, L. M. (2007). From insult to injury: Explaining the impact of incivility. Basic and Applied Social Psychology, 29, 335-350. https://doi.org/10.1080/01973530701665108

Collins, N. L., \& Miller, L. C. (1994). Self-disclosure and liking: A meta-analytic review. Psychological Bulletin, 116, 457-475. https://doi.org/10.1037/0033-2909.116.3.457

Cortina, L. M. (2008). Unseen injustice: Incivility as modern discrimination in organizations. The Academy of Management Review, 33, 55-75. https://doi.org/10.2307/20159376

Cortina, L. M., Kabat-Farr, D., Leskinen, E. A., Huerta, M., \& Magley, V. J. (2013). Selective incivility as modern discrimination in organizations: Evidence and impact. Journal of Management, 39, 1579-1605. https://doi.org/10.1177/0149206311418835

Crandall, C. S., \& Eshleman, A. (2003). A justification-suppression model of the expression and experience of prejudice. Psychological Bulletin, 129, 414-446. https://doi.org/10.1037/0033-2909. 129.3.414

Crocker, J., \& Major, B. (1989). Social stigma and self-esteem: The self-protective properties of stigma. Psychological Review, 96, 608-630. https://doi.org/10.1037/0033-295X.96.4.608

Czopp, A. M., Monteith, M. J., \& Mark, A. Y. (2006). Standing up for a change: Reducing bias through interpersonal confrontation. Journal of Personality and Social Psychology, 90, 784-803. https: //doi.org/10.1037/0022-3514.90.5.784

DeJong, W. (1980). The stigma of obesity: The consequences of naive assumptions concerning the causes of physical deviance. Journal of Health and Social Behavior, 21, 75-87. https://doi.org/10. $2307 / 2136696$

Devine, P. G., \& Monteith, M. J. (1999). Automaticity and control in stereotyping. In S. Chaiken \& Y. Trope (Eds.), Dual-process theories in social psychology (pp. 339-360). New York, NY: Guilford Press. https://doi.org/10.1080/09585192.2011.561212

Dovidio, J. F., \& Gaertner, S. L. (1998). On the nature of contemporary prejudice: The causes, consequences, and challenges of aversive racism. In J. L. Eberhardt \& S. T. Fiske (Eds.), Confronting racism: The problem and the response (pp. 3-32). Thousand Oaks, CA: Sage.

Foulk, T., Woolum, A., \& Erez, A. (2016). Catching rudeness is like catching a cold: The contagion effects of low-intensity negative behaviors. Journal of Applied Psychology, 101, 50-67. https:// doi.org/10.1037/apl0000037

Fox, S., \& Stallworth, L. (2005). Racial/ethnic bullying: Exploring links between bullying and racism in the U.S. workplace. Journal of Vocational Behavior, 66, 438-456. https://doi.org/10.1016/j.jvb. 2004.01.002

Gulker, J. E., Mark, A. Y., \& Monteith, M. J. (2013). Confronting prejudice: The who, what, and why of confrontation effectiveness. Social Influence, 8, 280-293. https://doi.org/10.1080/15534510. 2012.736879 
Hebl, M. R., Foster, J., Mannix, L. M., \& Dovidio, J. F. (2002). Formal and interpersonal discrimination: A field study of bias toward homosexual applicants. Personality and Social Psychology Bulletin, 28, 815-825. https://doi.org/10.1177/0146167202289010

Hebl, M. R., \& Kleck, R. E. (2002). Acknowledging one's stigma in the interview setting: Effective strategy or liability? Journal of Applied Social Psychology, 32, 223-249. https://doi.org/10.1111/j. 1559- 1816.2002.tb00214.x

Hebl, M., Ruggs, E. N., Martinez, L. R., Trump-Steele, R., \& Nittrouer, C. (2015). Understanding and reducing interpersonal discrimination in the workplace. In T. D. Nelson (Ed.), Handbook of prejudice, stereotyping, and discrimination (2nd ed., pp. 387-407). Hove, UK: Psychology Press.

Helson, H. (1964). Current trends and issues in adaptation-level theory. American Psychologist, 19, 26-38. https://doi.org/10.1037/h0040013

Iyer, A., Leach, C. W., \& Crosby, F. J. (2003). White guilt and racial compensation: The benefits and limits of self-focus. Personality and Social Psychology Bulletin, 29, 117-129. https://doi.org/10. 1177/0146167202238377

Jensen, J. M., Patel, P. C., \& Raver, J. L. (2014). Is it better to be average? High and low performance as predictors of employee victimization. Journal of Applied Psychology, 99, 296-309. https://doi. org/10.1037/a0034822

Johnson, M. A., \& Griffith, M. D. (2016, April). An obesity paradox for mistreatment? Body fat's impact on health outcomes of workplace mistreatment. Paper presented at the 31st Annual Conference of the Society for Industrial and Organizational Psychology, Anaheim, CA.

Jones, K. P., Peddie, C. I., Gilrane, V. L., King, E. B., \& Gray, A. (2016). Not so subtle: A meta-analysis of the correlates of subtle and overt discrimination. Journal of Management, 42, 1588-1613. https: //doi.org/10.1177/0149206313506466

Jones, K, P., Sabat, I. E., Lindsey, A. P., Ahmad, A. S., \& Arena, D. F. (2016, April). Killing me softly: How subtle discrimination pushes minority women out. In K. P. Jones (Chair), The trouble with subtle: Boundary conditions of subtle discrimination outcomes. Symposium conducted at the 31st Annual Conference of the Society for Industrial and Organizational Psychology, Anaheim, CA.

King, E. B., \& Ahmad, A. S. (2010). An experimental field study of interpersonal discrimination toward Muslim job applicants. Personnel Psychology, 63, 881-906. https://doi.org/10.1111/j. 1744-6570.2010.01199.x

King, E. B., \& Cortina, J. M. (2010). The social and economic imperative of lesbian, gay, bisexual, and transgendered supportive organizational policies. Industrial and Organizational Psychology: Perspectives on Science and Practice, 3, 69-78. https://doi.org/10.1111/j.1754-9434.2009.01201.x

King, E., \& Gilrane, V. (2015). Social science strategies for managing diversity: Industrial and organizational opportunities to enhance inclusion. Retrieved from http://www.siop.org/UserFiles/Image/ SHRM_SIOP_Diversity.pdf

Konrad, A. M., Seidel, M. D. L., Lo, E., Bhardwaj, A., \& Qureshi, I. (2015). Variety, dissimilarity, and status centrality in MBA networks: Is the minority or the majority more likely to network across diversity? Academy of Management Learning \& Education. Advance online publication. https: //doi.org/10.5465/amle.2015.0256

Lindsey, A., King, E., Cheung, H., Hebl, M., Lynch, S., \& Mancini, V. (2015). When do women respond against discrimination? Exploring factors of subtlety, form, and focus. Journal of Applied Social Psychology, 45, 649-661. https://doi.org/10.1111/jasp.12326

Lindsey, A., King, E., McCausland, T., Jones, K., \& Dunleavy, E. (2013). What we know and don't: Eradicating employment discrimination 50 years after the Civil Rights Act. Industrial and Organizational Psychology: Perspectives on Science and Practice, 6, 391-413. https://doi.org/10.1111/ iops. 12075

Lucas, R. E. (2007). Adaptation and the set-point model of subject well-being: Does happiness change after major life events? Current Directions in Psychological Science, 16, 75-79. https://doi.org/ 467-8721.2007.00479.x

Lueke, A., \& Gibson, B. (2016). Brief mindfulness meditation reduces discrimination. Psychology of Consciousness: Theory, Research, and Practice, 3, 34-44. https://doi.org/10.1037/cns0000081 
Lyons, B. J., Martinez, L. R., Ruggs, E. N., Hebl, M. R., Ryan, A. M., O’Brien, K. R., \& Roebuck, A. (2016). To say or not to say: Different strategies of acknowledging a visible disability. Journal of Management. Advance online publication. https://doi.org/10.1177/0149206316638160

Madera, J. M., \& Hebl, M. R. (2012). Discrimination against facially stigmatized applicants in interviews: An eye-tracking and face-to-face investigation. Journal of Applied Psychology, 97, 317-330. https://doi.org/10.1037/a0025799

Madera, J. M., Hebl, M. R., \& Martin, R. C. (2009). Gender and letters of recommendation for academia: Agentic and communal differences. Journal of Applied Psychology, 94, 1591-1599. https://doi.org/10.1037/a0016539

Manne, S., Ostroff, J., Rini, C., Fox, K., Goldstein, L., \& Grana, G. (2004). The interpersonal process model of intimacy: The role of self-disclosure, partner disclosure, and partner responsiveness in interactions between breast cancer patients and their partners. Journal of Family Psychology, 18, 589-599. https://doi.org/10.1037/0893-3200.18.4.589

McConahay, J. B. (1983). Modern racism and modern discrimination: The effects of race, racial attitudes, and context on simulated hiring decisions. Personality and Social Psychology Bulletin, 9, 551-558. https://doi.org/10.1177/0146167283094004

Milkman, K. L., Akinola, M., \& Chugh, D. (2015). What happens before? A field experiment exploring how pay and representation differentially shape bias on the pathway into organizations. Journal of Applied Psychology, 100, 1678-1712. https://doi.org/10.1037/apl0000022

Miller, D. P. Jr., Spangler, J. G., Vitolins, M. Z., Davis, S. W., Ip, E. H., Marion, G. S., \& Crandall, S. J. (2013). Are medical students aware of their anti-obesity bias? Academic Medicine, 88, 978-982. https://doi.org/10.1097/ACM.0b013e318294f817

Miner-Rubino, K., \& Cortina, L. M. (2007). Beyond targets: Consequences of vicarious exposure to misogyny at work. Journal of Applied Psychology, 92, 1254-1269. https://doi.org/10.1037/ 0021-9010.92.5.1254

Monteith, M. J., Voils, C. I., \& Ashburn-Nardo, L. (2001). Taking a look underground: Detecting, interpreting, and reacting to implicit racial biases. Social Cognition, 19, 395-417. https://doi.org/ 10.1521/soco.19.4.395.20759

Morgan, W. B., Walker, S. S., Hebl, M. R., \& King, E. B. (2013). A field experiment: Reducing interpersonal discrimination toward pregnant job applicants. Journal of Applied Psychology, 98, 799-809. https://doi.org/10.1037/a0034040

Mossakowski, K. N. (2003). Coping with perceived discrimination: Does ethnic identity protect mental health? Journal of Health and Social Behavior, 44, 318-331. https://doi.org/10.2307/1519782

Neel, R., Neufeld, S. L., \& Neuberg, S. L. (2013). Would an obese person whistle Vivaldi? Targets of prejudice self-present to minimize appearance of specific threats. Psychological Science, 24, 678687. https://doi.org/10.1177/0956797612458807

Noh, S., Beiser, M., Kaspar, V., Hou, F., \& Rummens, J. (1999). Perceived racial discrimination, depression, and coping: A study of Southeast Asian refugees in Canada. Journal of Health and Social Behavior, 40, 193-207. https://doi.org/10.2307/2676348

Noh, S., \& Kaspar, V. (2003). Perceived discrimination and depression: Moderating effects of coping, acculturation, and ethnic support. American Journal of Public Health, 93, 232-238. https://doi. org/10.2105/AJPH.93.2.232

O'Reilly, J., Aquino, K., \& Skarlicki, D. (2016). The lives of others: Third parties' responses to others' injustice. Journal of Applied Psychology, 101, 171-189. https://doi.org/10.1037/apl0000040

Perry, S. P., Murphy, M. C., \& Dovidio, J. F. (2015). Modern prejudice: Subtle, but unconscious? The role of bias awareness in Whites' perceptions of personal and other's biases. Journal of Experimental Social Psychology, 61, 64-78. https://doi.org/10.1016/j.jesp.2015.06.007

Phelan, S. M., Dovidio, J. F., Puhl, R. M., Burgess, D. J., Nelson, D. B., Yeazel, M. W.,. . Ryn, M. V. (2014). Implicit and explicit weight bias in a national sample of 4,732 medical students: The medical student CHANGES study. Obesity, 22, 1201-1208. https://doi.org/10.1002/oby.20687

Porath, C. L., \& Erez, A. (2009). Overlooked but not untouched: How rudeness reduces onlookers' performance on routine and creative tasks. Organizational Behavior and Human Decision Processes, 109, 29-44. https://doi.org/10.1016/j.obhdp.2009.01.003 
Raver, J. L., \& Nishii, L. H. (2010). Once, twice, or three times as harmful? Ethnic harassment, gender harassment, and generalized workplace harassment. Journal of Applied Psychology, 95, 236-254. https://doi.org/10.1037/a0018377

Reason, R. D., Millar, E. A. R., \& Scales, T. C. (2005). Toward a model of racial justice ally development. Journal of College Student Development, 46, 530-546. https://doi.org/10.1353/csd.2005. 0054

Reich, T. C., \& Hershcovis, M. S. (2015). Observing workplace incivility. Journal of Applied Psychology, 100, 203-215. https://doi.org/10.1037/a0036464

Rivera, L. A. (2012). Diversity within reach: Recruitment versus hiring in elite firms. Annals of the American Academy of Political and Social Science, 639, 71-90. https://doi.org/10.1177/ 0002716211421112

Rudman, L. A., \& Phelan, J. E. (2008). Backlash effects for disconfirming gender stereotypes in organizations. Research in Organizational Behavior, 28, 61-79. https://doi.org/10.1016/j.riob.2008.04. 003

Sabat, I. E., Martinez, L. R., \& Wessel, J. L. (2013). Neo-activism: Engaging allies in modern workplace discrimination reduction. Industrial and Organizational Psychology, 6, 480-485. https://doi.org/ 10.1111/iops.12089

Salvatore, J., \& Shelton, J. N. (2007). Cognitive costs of exposure to racial prejudice. Psychological Science, 18, 810-815. https://doi.org/10.1111/j.1467-9280.2007.01984.x

Saul, J. (2013). Implicit bias, stereotype threat, and women in philosophy. In K. Hutchison \& F. Jenkins (Eds.), Women in philosophy: What needs to change? (pp. 39-60). Oxford, UK: Oxford University Press. https://doi.org/10.1093/acprof:oso/9780199325603.003.0003

Schmader, T., Croft, A., Scarnier, M., Lickel, B., \& Mendes, W. B. (2012). Implicit and explicit emotional reactions to witnessing prejudice. Group Processes \& Intergroup Relations, 15, 379-392. https://doi.org/10.1177/1368430211426163

Schmidt, F. L., \& Hunter, J. E. (1998). The validity and utility of selection methods in personnel psychology: Practical and theoretical implications of 85 years of research findings. Psychological Bulletin, 124, 262-274. https://doi.org/10.1037/0033-2909.124.2.262

Shelton, J. N., Richeson, J. A., Salvatore, J., \& Hill, D. M. (2006). Silence is not golden: Intrapersonal consequences of not confronting prejudice. In S. Levin \& C. V. Laar (Eds.), Social stigma and group inequality: Social psychological perspectives (pp. 65-81). Mahwah, NJ: Erlbaum.

Shelton, J., \& Stewart, R. E. (2004). Confronting perpetrators of prejudice: The inhibitory effects of social costs. Psychology of Women Quarterly, 28, 215-223. https://doi.org/10.1111/j.1471-6402. 2004.00138.x

Singletary, S. L., \& Hebl, M. R. (2009). Compensatory strategies for reducing interpersonal discrimination: The effectiveness of acknowledgments, increased positivity, and individuating information. Journal of Applied Psychology, 94, 797-805. https://doi.org/10.1037/a0014185

Smart, R, L., \& Leary, M. R. (2009). Reactions to discrimination, stigmatization, ostracism, and other forms of interpersonal rejection: A multimotive model. Psychological Review, 116, 365-383 https: //doi.org/10.1037/a0015250

Swim, J. K., Aikin, K. J., Hall, W. S., \& Hunter, B. A. (1995). Sexism and racism: Old-fashioned and modern prejudices. Journal of Personality and Social Psychology, 68, 199-214. https://doi.org/10. 1037/0022-3514.68.2.199

Taylor, K. (2014). Thoughts about allyship, accountability and resistance. Retrieved from Victoria Sexual Assault Centre website: http://vsac.ca/2014/10/thoughts-allyship-accountability-resistance/

Turillo, C. J., Folger, R., Lavelle, J. J., Umphress, E. E., \& Gee, J. O. (2002). Is virtue its own reward? Self-sacrificial decisions for the sake of fairness. Organizational Behavior and Human Decision Processes, 89, 839-865. https://doi.org/10.1016/S0749-5978(02)00032-8

Turner, R. N., Hewstone, M., \& Voci, A. (2007). Reducing explicit and implicit outgroup prejudice via direct and extended contact: The mediating role of self-disclosure and intergroup anxiety. Journal of Personality and Social Psychology, 93, 369-388. https://doi.org/10.1037/0022-3514.93. 3.369

Valian, V. (1998). Why so slow? The advancement of women. Cambridge, MA: MIT Press. 
Van Laer, K., \& Janssens, M. (2011). Ethnic minority professionals' experiences with subtle discrimination in the workplace. Human Relations, 64, 1203-1227. https://doi.org/10.1177/ 0018726711409263

Wessel, J. L., Hagiwara, N., Ryan, A. M., \& Kermond, C. M. Y. (2014). Should women applicants "man up" for traditionally masculine fields? Effectiveness of two verbal identity management strategies. Psychology of Women Quarterly, 39, 243-255. https://doi.org/10.1177/0361684314543265

Word, C. O., Zanna, M. P., \& Cooper, J. (1974). The nonverbal mediation of self-fulfilling prophecies in interracial interaction. Journal of Experimental Social Psychology, 10, 109-120. https://doi.org/ 10.1016/0022-1031(74)90059-6 